\title{
A TOOL FOR THE ASSESSMENT OF THERMAL EFFICIENCY OF IDEAL DIESEL CYCLES, PROVIDED TO FUTURE MARINE ENGINEERS
}

\author{
Ionela Ticu $^{1}$, Elena Gogu ${ }^{2}$ \\ ${ }^{1}$ Constanta Maritime University, Faculty of Naval Electro-Mechanics, 104 Mircea cel Batran Street, 900663, Constanta, \\ Romania, e-mail address: ionela.ticu@yahoo.com \\ ${ }^{2}$ Gheorghe Duca" Technological High School, Vifor Haiducul Street, No 34, Constanta, Romania, e-mail address: \\ goguelena@yahoo.com
}

\begin{abstract}
Diesel engines are a type of internal combustion engine widely spread in the maritime sector. In a world depending on fossil fuels, the challenge faced by scientists and professionals consists in the efficient use of this kind of fuels. The future of these engines strongly depends on the efficiency enhancement. Future mechanical engineers have to be trained in order to gain engineering judgement and enterprising attitude. In this respect, this paper deals with a theoretical study focused on the improvement of the efficiency of the ideal Diesel cycle. This type of study was recently introduced in Constanta Maritime University, within Thermodynamics seminar activities, delivered to future marine engineers, enrolled in their third semester. This study will reveal the fact that the efficiency of Diesel cycles is affected by the variation of compression ratio, cut off ratio and specific heats ratio. The results obtained will show that, for the ranges taken into discussion, thermal efficiency might be enhanced by the rise of compression ratio and specific heat ratio values and by lowering cut off ratio values. The study is a predecessor of expensive and time costing experiences and it is also a guidance in the hand of future professionals - able to train them for real solutions.
\end{abstract}

Key words: diesel engines, performance, thermodynamics, students.

\section{INTRODUCTION}

Having in view the widening of the international fleet, the curricula of future marine engineers graduating from Constanta Maritime University is designed in order to guarantee the achievement of skills able to ensure the success of this personnel on board of ships [1], [2]. In the actual time, industries are featured by high energy consumptions and resources depletion, Thermodynamics being the discipline connecting these issues with environment protection [3].

Internal combustion engines are encountered in various applications due to their benefits: low initial cost, high power, good efficiencies, ability to fulfil emission regulations, match to available fuels; being so important for the maritime industry, this technology is subject of achieving higher performance amid new concern about low fuel consumption and ship gaseous emissions [4], [5].

In the present time, Diesel engines are met on the board of approximately $90 \%$ of the vessels all around the world; these engines use marine fuels, which are cheap but pollutant [6].
Their principle is based on the entry of the air in the combustion chamber, during the intake stoke, followed by the compression to a high pressure; the high temperature reached allows to the injected fuel to self ignite [7].

Many of mechanical engineering students do not fully understand the theory and analysis issues related to engines [8]. For a better understanding of the analysis of Diesel cycles, the air standard cycle is introduced firstly; the specific assumptions are as follows: air is an ideal gas, all four processes are reversible, heat losses and friction are neglected, specific heats are constant [9].

Future mechanical engineers have to be trained to accomplish with real situations, starting with a proper level of complexity and aiming to be reached the engineering judgement and enterprising attitude [10].

In this respect, this paper deals with a theoretical study focusing on the improvement of the efficiency of an ideal Diesel cycle, recently introduced in Constanta Maritime University, during Thermodynamics seminar activities, delivered to future marine engineers. The aim of this study is to offer to our undergraduates a clear image on the elements which affect the performance of 
Journal of Marine Technology and Environment the Diesel cycle, comprising calculations for which thermal efficiency is increasing.

The development of this study was given by the continuously need of curriculum revision with the purpose to ensure the ability to manage with real practical situations.

Such a study is welcomed when it defeats time consuming and expensive experiments.

\section{METHODS AND MATERIALS}

Internal combustion engines are subject of study for the future marine engineers enrolled in Constanta Maritime University, Marine Electromechanics Faculty Undergraduate Electromechanics Programme.

Future marine engineers are able to gain a wide set of knowledge on this type of engines during different disciplines included in their curricula: Thermodynamics I, Internal Combustion Engines Processes and Characteristics I, II, Internal Combustion Engines Components and Ancillary Systems I, II and Exploitation, Repair and Maintenance of Internal Combustion Engines.

Their descriptions in provided bellow:

Thermodynamics I

Type: in profile; Course hours: 42; Applications hours: 28; Number of credit points: 5; Term: 2

Subject category: obligatory

Objectives: gaining theoretical knowledge and calculus understanding for the application of thermodynamics laws in order to manage with processes developed in thermal machines.

Internal Combustion Engines Processes and Characteristics I, II

Type: specialty; Course hours: 84; Applications hours: 42 ; Number of credit points: $5+5$; Term: 6,7

Subject category: optional

Objectives: possession of sufficient theoretical knowledge to carry out the part of a watch keeping engineer's responsibilities concerned with the efficient operation of marine heat engines and thermodynamic processes and, on completion of a mandatory seagoing service, they will process the corresponding knowledge to carry out the part of a chief engineer in a safe and efficient manner; possession of knowledge specific to engine operational parameters determination and the indicator diagram plotting for a real engine.

Internal Combustion Engines Components and Ancillary Systems I, II

Type: specialty; Course hours:112; Applications hours: 56; Number of credit points:7+6; Term: 7,8

Subject category: optional

Objectives: on completion of both courses and seagoing phase, students should posses sufficient knowledge to operate the main and auxiliary machinery normally installed in diesel - powered ships in a safe and efficient manner; acquiring constructive solutions and
Year 2021, Vol.II

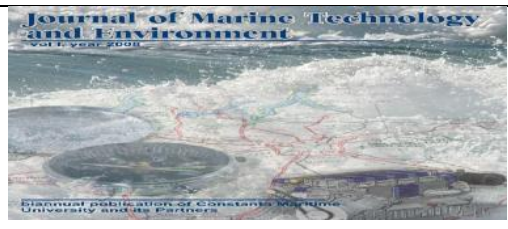

applications to detect failures that can occur in marine engine operation.

Exploitation, Repair and Maintenance of Internal Combustion Engines

Type: specialty; Course hours: 56; Applications hours: 28; Number of credit points: 6 ; Term: 8

Subject category: obligatory

Objectives: presentation of: principles and methods for Diesel engine diagnosis; faults and overhaul for marine Diesel engines and auxiliary system; procedures for repair and maintenance of naval engines and auxiliary systems; basic principles for operating and control of marine Diesel engines; duties and organization of activities on board and in engine room in accordance with IMO, ASM, STCW and classifications society recommendations; principles for reliability maintenance of engines, taking into account different qualities of working agents; steps to be fooling for repair and overhaul the plant in the machinery space; safety procedures for preparing and starting the machinery; procedures for operate the marine engine in normal and emergency conditions.

Seen the complexity of the topics discussed, Thermodynamics I has the task to provide a strong theoretical base for understanding the actions specific to the performance enhancement of the Diesel cycles.

In this respect, the theoretical study described in the following and the interpretation of the results offer to future professionals a perspective on the solutions for achieving higher thermal efficiencies - a situation for which lower energy and fuel consumptions are reached [11].

In Figure 1 it is given the cycle of an ideal Diesel cycle; it is sein that the heat is introduced during the isobaric combustion, while the heat is evacuated with the exhaust gases.

The relationships related to this study are given below [12].

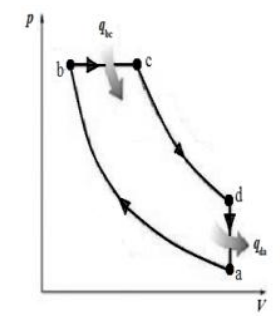

Figure 1 The ideal Diesel cycle in p-v diagram

Since processes $\mathrm{a}-\mathrm{b}$ and $\mathrm{c}-\mathrm{d}$ occur without heat exchange, on the first law basis:

$$
\begin{aligned}
& -w_{a b}=u_{b}-u_{a} \\
& -w_{c d}=u_{d}-u_{c}
\end{aligned}
$$

where: 


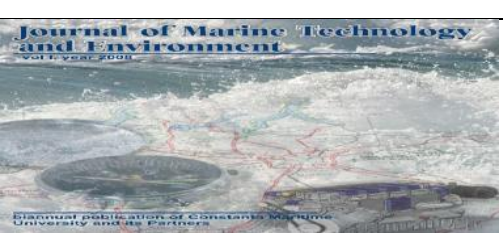

Journal of Marine Technology and Environment Year 2021, Vol.II

w - work

$\mathrm{u}-$ internal energy.

During combustion:

$$
w_{b c}=p_{b}\left(v_{c}-v_{b}\right)
$$

where:

$\mathrm{p}-$ pressure

$\mathrm{v}$ - specific volume.

According to the first law, for the combustion process:

$$
q_{b c}=w_{b c}+\left(u_{c}-u_{b}\right)
$$

or:

$$
q_{b c}=h_{c}-h_{b}
$$

where:

$\mathrm{h}$ - enthalpy.

For the heat rejection:

$$
q_{d a}=u_{a}-u_{d} .
$$

For the entire Diesel cycle:

$$
q_{b c}+q_{d a}=w_{a b}-w_{c d}
$$

The assessment of the two amounts of heat:

$$
\begin{aligned}
& Q_{b c}=c_{p}\left(T_{c}-T_{b}\right) \\
& Q_{d a}=c_{v}\left(T_{d}-T_{a}\right)
\end{aligned}
$$

where:

$\mathrm{c}_{\mathrm{p}} / \mathrm{c}_{\mathrm{v}}-$ specific heats at $\mathrm{p}=$ const $/ \mathrm{v}=$ const.

The ideal thermal efficiency:

$$
\eta_{t}=1-\frac{Q_{d a}}{Q_{b c}}=1-\frac{c_{v}\left(T_{d}-T_{a}\right)}{c_{p}\left(T_{c}-T_{b}\right)}
$$

Since the exponent " $k$ " is the ratio of the specific heats $c_{p} / c_{v}$, results that:

$$
\eta_{t}=1-\frac{T_{d}-T_{a}}{k\left(T_{c}-T_{b}\right)}
$$

The temperature at the end of the isentropic compression:

$$
T_{b}=T_{a} \varepsilon^{k-1}
$$

where:

$$
\begin{aligned}
& \varepsilon-\text { compression ratio } \\
& \varepsilon=\frac{V_{a}}{V_{b}} .
\end{aligned}
$$

The temperature at the end of the combustion:

$$
T_{c}=T_{b} \rho=T_{a} \rho \varepsilon^{k-1},
$$

where:

$$
\begin{gathered}
\rho-\text { cut off ratio } \\
\rho=V_{3} / V_{2} .
\end{gathered}
$$

For the isentropic expansion:

$$
\frac{T_{d}}{T_{c}}=\left(\frac{V_{c}}{V_{d}}\right)^{k-1}
$$

or:

$$
\frac{T_{d}}{T_{c}}=\left(V_{c} / V_{b}\right)^{k-1}\left(V_{b} / V_{d}\right)^{k-1} .
$$

So that:

$$
\eta_{t}=1-\frac{1}{\varepsilon^{k-1}} \cdot \frac{\rho^{k}-1}{k(\rho-1)}
$$

From equation (16) results that the thermal efficiency of the ideal cycle depends on three important parameters:

- cut off ratio,

- specific heat ratio,

- compression ratio.

\section{RESULTS AND DISCUSSIONS}

In the following, will be seen the influence of compression ratio, cut off ratio and specific heats ratio variations on the performance of the cycle.

The cut off ratio will vary in the range $(1.5-3)$ and the compression ratio in the range $(13-19)$.

The specific heats ratio will take the following values: 1.22, 1.33 and 1.4 (see Figure 2, Figure 3, Figure 4).

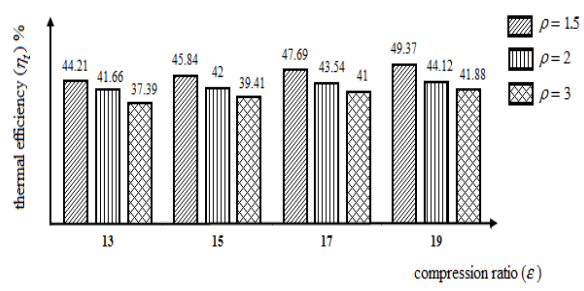

Figure 2 Influence of $\rho$ and variation on $\eta_{t}$, for $\mathrm{k}=1.22$

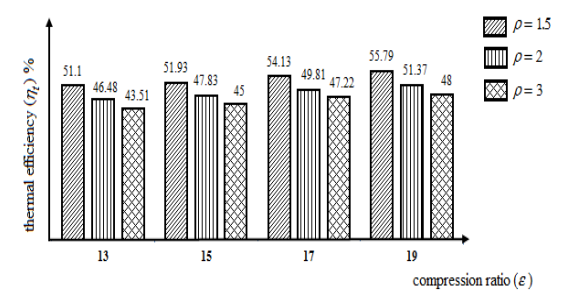

Figure 3 Influence of $\rho$ and variation on $\eta_{t}$, for $\mathrm{k}=1.33$

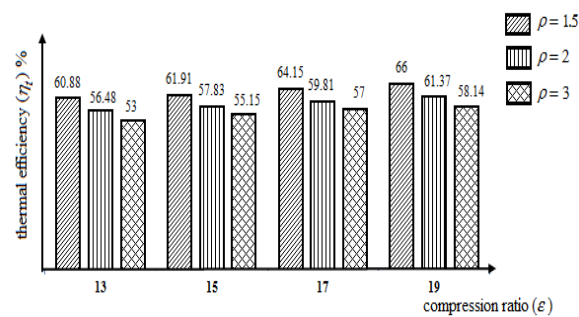

Figure 4 Influence of $\rho$ and variation on $\eta_{t}$, for $\mathrm{k}=1.4$ 


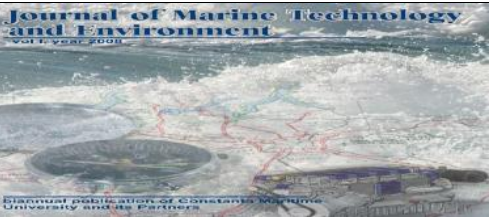

Journal of Marine Technology and Environment

From the above plots results that, in all the situations, the thermal efficiency increase together with the increment of compression ratio and specific heats ratio values. On the contrary, the thermal efficiency of the cycle decreases with the increment of the cut off ratio.

This in due to the fact that the engine is pushing more on the piston. Achieving a higher combustion efficiency due to the compression ratio rise, a more significant amount of energy will be available. The maximum thermal efficiency is sein at compression ratio of 19.

The increase of specific heats ratio leads to an increased work output so that the thermal efficiency will be improved. The maximum thermal efficiency is obtained at specific heats ratio of 1.4.

The variation of cut off ratio on the performance of the cycle is incontestable. When the cut off ratio values increase, the power input decrease, because the difference between the heat introduced and the heat evacuated decrease; the lowest thermal efficiency was found for the highest cut off ratio $(\rho=3)$.

For the values considered in the theoretical study above developed results that the best thermal efficiency value is found when the compression ratio is the highest (19) and the specific heats ratio as well (1.4), while the cut off ratio is at its minimum (1.5); the best thermal efficiency value found is $66 \%$.

\section{CONCLUSIONS}

A theoretical study on the thermal efficiency improvement of ideal Diesel cycles it is needed for the future marine engineers in order to gain experience on operating conditions, in an efficient manner.

Such a study brings into discussion the elements which strongly influence the thermal efficiency of this engine: compression ratio, cut off ratio and specific heats ratio. The results obtained from the above study can be concluded as: for the numerical conditions considered, the thermal efficiency is improved by increasing the compression ratio and specific heats ratios and by decreasing the cut off ratio. Thus, the maximum efficiency $(66 \%)$ is reached for $\varepsilon=19, \mathrm{k}=1.4$ and $\rho=$ 1.5 .

The conclusions of the study are able to offer an important guidance for performance assessment and improvement of Diesel cycles, from the beginning of future marine engineers education.

\section{REFERENCES}

[1] Memet F., 2014, An experience in refrigeration calculation carried out by future marine engineers in CMU, CMU Annals, Vol 22, Year XV, pp 61 -64.
Year 2021, Vol.II

[2] Memet F, 2017, How to approach the Otto cycle theory during the undergraduate thermodynamics course in CMU, Journal of Marine Technology and Environment, VOL 2, pp 65-68.

[3] Memet F, 2015, A point of view on the role of thermodynamics in the education of future environmental engineers, CMU Annals, Vol 24, Year XVI, pp $79-82$.

[4] Caton J.A., 2018, The thermodynamics of internal combustion engines: Examples of insights, Inventions, Vol. 3, pp 1-30.

[5] Guan C., Theotokatos G., Chen H, 2015, Analysis of two stroke marine diesel engine operation including turbochanger cut- out by using a zero-dimensional model, Energies, Vol. 8, pp 5738- 5764.

[6] Lamas M.I., Rodriguez C. G., 2012, Emissions form maritime engines and NOx reduction methods, Journal of Maritime Research, Vol IX (1), pp 77-82.

[7] Akash B. A., 2001, Effect of heat transfer on the performance of an air- standard Diesel Cycle, Int. Communications in Heat and Mass Transfer, 28 (1), pp 87- 95

[8] Kirkpatrick A.L.A., Lee A. Willson B, 1997, The engine in engineering- Development of thermal/ fluids web based applications, Frontiers in Education, Annual, Vol 2, pp 744-747.

[9] Hou S.S., Lin J.C., 2011, Performance analysis of an Diesel cycle under the restriction of maximum cycle temperature with considerations of heat loss friction and variable specific heats, Acta Physica Polonica A, Vol 120 (16), pp 979-986.

[10] Showers I.A, Jack T.K, Etebu O.M.O., 2014, Computer applications in mechanical engineering education- Case 1: Diesel engine performance analysis with MATLAB, Int. J. of Engineering Trends and Technology, Vol. 11 (10), pp 459-469.

[11] Furfari S. A., 2016, Energy efficiency of engines and appliancies for transport on land, water and in air, Supplement, Vol 45, pp 63-68.

[12] Yildizhan S, Karaman V, Ozcanli M, Serin H., 2016, Calculation and optimising of brake thermal efficiency of Diesel engines based on theoretical Diesel cycle parameters, Int. Journal of Engineering Technologies, Vol. 2 (3), pp100-104. 